\title{
Atividades experimentais no ensino da química: distanciamentos e aproximações da avaliação de quarta geração
}

\section{Experimental activities in the teaching of chemistry: detachment and appropriation of the fourth generation of evaluation}

Rosivânia da Silva Andrade ${ }^{1}$. Kilma da Silva Lima Viana ${ }^{2}$

\begin{abstract}
Resumo: A experimentação apresenta contribuições significativas para o Ensino da Química, mas não é possível inovar o ensino se a sua avaliação se prende aos moldes tradicionais, quantitativos e classificatórios. Assim, esse estudo busca analisar o processo avaliativo vivenciado em aulas experimentais pelos professores de Química do Ensino Médio Integrado do Instituto Federal de Pernambuco, campus Vitória. A metodologia de pesquisa foi organizada como um Ciclo da Experiência Kellyana e a análise de dados teve como base as Gerações da Avaliação propostas por Guba e Lincoln. Ao final da pesquisa os sujeitos pesquisados puderam rever suas concepções de avaliação e alguns apresentaram concepções e práticas inovadoras, características de uma Avaliação de Quarta Geração. Embora outros professores tivessem apresentado prática mais distante da Quarta Geração, após a vivência da experiência, puderam se aproximar um pouco mais de concepções com indicativos da perspectiva da avaliação mediadora.
\end{abstract}

Palavras-chave: Ensino de química. Ensino médio. Experimentação. Avaliação da aprendizagem.

\begin{abstract}
Experimentation presents significant contributions to the teaching of Chemistry, but it is not possible to innovate in teaching if its evaluation follows traditional, quantitative and classificatory models. Thus, this study seeks to analyze the evaluative process experienced in experimental classes by Chemistry teachers of Integrated High School of the Federal Institute of Pernambuco - IFPE Vitória Campus. Thus, we organized the research methodology as a Kellyan Experience Cycle and we based the analysis of the data on Generations of Assessment proposed by Guba and Lincoln. At the end of our research, the subjects of the sample were able to review their conceptions of evaluation. Some of them presented concepts and innovative practices, the characteristics of a Fourth Generation evaluation, and others teachers presented a practice some way from the Fourth Generation, and others, after having the experience, were able to get a little closer with indicators related to the perspective of mediating evaluation.
\end{abstract}

Keywords: Chemistry teaching. High School. Experimentation. Learning evaluation.

\footnotetext{
${ }^{1}$ Universidade Federal de Pernambuco (UFPE), Caruaru, PE, Brasil. E-mail: <rosivaniandrade@gmail.com>.

${ }^{2}$ Instituto Federal de Educação, Ciência e Tecnologia de Pernambuco (IFPE), Departamento de Desenvolvimento Educacional, Vitória de Santo Antão, PE, Brasil.
} 


\section{Introdução}

A forma como a aprendizagem é avaliada é de fundamental importância para se ter uma resposta plausível sobre a consolidação do processo de ensino-aprendizagem. Proporcionando, dessa maneira, a formação de estudantes críticos, reflexivos e socialmente responsáveis, mantendo-se na inércia da reprodução. No entanto, cada vez mais a sociedade exige estudantes que se posicionem, julguem e tomem decisões, e que sejam responsabilizados por isso. (BRASIL, 2006).

No entanto, o ensino da Química, tem apresentado práticas que estão relacionadas com as abordagens tradicionais de ensino (LIMA, 2008; MIZUKAMI, 1986). Nesse contexto, o resgate da natureza experimental da Química e o seu diálogo com a realidade podem ser veículos de mudança. Mas é preciso ressaltar que a utilização de experimentos nas aulas de Química, por si só, não tem impactos positivos em relação à aprendizagem. As aulas experimentais podem ser um alicerce, que aliadas a práticas avaliativas mediadoras e reguladoras auxiliam, significativamente, no processo de aprendizagem dos estudantes.

Assim, a utilização de atividades experimentais nas aulas de Química, segundo Alves Filho (2000) possui o objetivo pedagógico de aperfeiçoar o processo de ensino-aprendizagem, tornando-o interativo, no qual os estudantes podem participar de forma ativa. Isso é possível porque a natureza dessa ciência é, essencialmente, experimental. Além disso, as novas perspectivas para o Ensino Médio dizem que a Química deve ser valorizada, na qualidade de instrumento cultural e essencial na educação humana, como meio coparticipante da interpretação do mundo e da ação responsável na realidade (BRASIL, 2006). E para que isso se concretize, segundo Freire (1996), a prática docente deve reforçar a capacidade crítica do educando, sua curiosidade e sua insubmissão.

Desse modo, o professor, diante da atividade experimental, deve se comportar como um mediador, pois a sua ajuda pedagógica é fundamental para que ocorram intervenções e proposições durante a realização da prática, proporcionando mais interatividade, dinamismo e reflexão. Extrapolando, dessa forma, a visão externa, quantitativa e empírica, as quais ainda são muito frequentes em salas de aula do Ensino Médio. Nesse contexto, para que ocorra mudança no ensino da Química, as formas avaliativas vivenciadas nessa ciência também precisam mudar. Uma vez que não é possível inovar o ensino se a sua avaliação se prende aos moldes tradicionais, quantitativos, classificatórios e excludentes. (VIANA, 2014).

Portanto, a avaliação se torna inovadora e indispensável para não só a aprendizagem crítica e de significados, mas também da compreensão e reflexão da prática do educador como agente mediador entre os conhecimentos prévios dos estudantes e o novo conhecimento a ser apreendido. Porém, não são todos os professores que assumem a avaliação como reflexão da sua prática, nem tampouco sobre a sua importância na construção do conhecimento crítico e de significados. Dessa forma, a avaliação se apresenta de diversas formas nas salas de aula, variando, a partir das concepções de cada professor.

Diante desse contexto, surge o questionamento: considerando que as práticas experimentais são mais dinâmicas e tem características mais emergentes relacionadas às novas perspectivas de ensino, quais as gerações de avaliação as práticas experimentais estão relacionadas? Nessa perspectiva, essa pesquisa teve como objetivo analisar o processo avaliativo vivenciado em aulas experimentais pelos professores de Química. Para isso, a metodologia de pesquisa foi organizada como um Ciclo da Experiência Kellyana (CEK) (KELLY, 1963) e a análise dos dados 
Atividades experimentais no ensino da química: ...

construídos a partir das etapas do CEK, tiveram como base teórica as Gerações da Avaliação propostas por Guba e Lincoln (1989).

\section{Metodologia}

Em função da natureza do objeto de estudo, a pesquisa é de natureza qualitativa, pois não foi orientada para produzir resultados estatisticamente relevantes generalizáveis, mas, antes de tudo, para compreender, em detalhes, o processo avaliativo vivenciado em aulas experimentais pelos professores de Química, afinal, a pesquisa qualitativa é uma atividade orientada a compreensão de fenômenos educativos (ESTEBAN, 2010; LUDKE; ANDRÉ, 1986). Dentre os métodos qualitativos descritos na literatura, adotamos a pesquisa-ação por ser uma metodologia de pesquisa orientada à prática educacional. (THIOLLENT, 1985; TRIPP, 2005).

Ressalta-se, que não consideramos a pesquisa como um processo neutro e nem os sujeitos como meros informantes dos dados, ao contrário, a intenção foi de encarar os sujeitos como partícipes da pesquisa. Dessa forma, foi essencial oportunizar que os professores pudessem, através da vivência da pesquisa, ressignificar suas próprias concepções. Diante disso, a organização da coleta e construção dos dados se deu como um Ciclo da Experiência Kellyana (CEK), tendo como proposta, o engajamento dos sujeitos no processo de análise, interpretação e reflexão da realidade vivida.

\section{Fundamentação Metodológica: CEK}

A Teoria dos Construtos Pessoais de Kelly (1963) apresenta como um de seus corolários, a experiência segundo o qual o sistema de construção de uma pessoa muda à medida que ela constrói réplicas de eventos e as confronta com as realidades do universo. Esse processo de reconstrução da realidade vivida está relacionado à ideia de Kelly sobre aprendizagem, segundo o qual, se a pessoa não aprende, ela não viveu a experiência. (LIMA, 2008; VIANA, 2014).

Kelly define dessa forma a experiência em um ciclo, Ciclo da Experiência Kellyana (CEK), composto por cinco etapas: Antecipação, Investimento, Encontro, Confirmação ou Desconfirmação e Revisão Construtiva. (BASTOS, 1992; BARROS; BASTOS, 2008).

O ciclo se inicia na etapa da Antecipação, momento em que a pessoa usa os construtos que possui para construir uma réplica do evento que vai encontrar e tenta antecipá-lo. Em seguida, a pessoa é engajada na etapa do Investimento, momento de melhorar a construção da réplica, através da inclusão de novos elementos. É o momento de preparação para o encontro com o evento, através de leituras, conversas e reflexões. Ao chegar à terceira etapa do CEK, o Encontro, é o momento de avaliar e testar suas próprias teorias e as hipóteses sobre o evento, o que conduz à quarta etapa, a Confirmação ou Desconfirmação. Nessa etapa, a pessoa confirma ou desconfirma suas hipóteses iniciais presentes na etapa da Antecipação e ampliadas na etapa do Investimento, a partir da vivência no evento de suas teorias pessoais. E fechando o CEK, a etapa da Revisão Construtiva, em que a pessoa é levada a reconstruir suas construções pessoais, ampliando seu repertório de construtos. (KELLY, 1963).

Portanto, os educadores e os educandos foram engajados no CEK proposto por Kelly (1963), para uma reflexão e reinterpretação da realidade vivida no desenvolvimento de aulas experimentais dentro de uma perspectiva de Avaliação de Quarta Geração, proporcionando, 
assim, a análise também das contribuições dessa Geração da Avaliação no processo de ensino -aprendizagem de conceitos em Química a partir de práticas experimentais.

\section{Campo e sujeitos da Pesquisa}

O campo de pesquisa envolveu uma instituição de Ensino Médio da Rede Federal. Os sujeitos envolvidos foram dois professores que ministram a disciplina de Química no Ensino Médio.

\section{Instrumentos da Pesquisa}

Como instrumentos de pesquisa foram utilizadas entrevistas semiestruturadas, além de observação e registro das práticas avaliativas dos educadores e seus instrumentos avaliativos na realização das atividades experimentais.

\section{Procedimentos da Pesquisa}

Os passos metodológicos seguiram as etapas descritas no Ciclo da Experiência Kellyana, os quais seguem abaixo:

Na primeira etapa, a Antecipação, foi realizado o primeiro encontro com os professores, quando foram efetuadas as entrevistas para identificar as concepções de avaliação dos professores de Química em relação às práticas experimentais.

Logo após, no Investimento, ocorreu o aprofundamento das discussões acerca da Avaliação da Aprendizagem em atividades experimentais, a partir do levantamento da literatura e de estudos acerca da temática.

$\mathrm{Na}$ terceira etapa, o Encontro, ocorreu a observação e registro da prática e dos instrumentos avaliativos utilizados pelos professores para construção do conhecimento.

Em seguida, na Confirmação ou Desconfirmação, foram analisados os distanciamentos e aproximações das práticas identificadas, observadas na terceira etapa, com a Avaliação de Quarta Geração.

$\mathrm{Na}$ quinta e última etapa, a Revisão Construtiva, ocorreu a avaliação do processo e as discussões dos principais pontos observados.

\section{Análise dos dados}

As análises dos dados coletados durante o desenvolvimento da pesquisa são apresentadas tendo como base teórica as Gerações da Avaliação propostas por Guba e Lincoln (1989).

Assim, as informações adquiridas a partir dos instrumentos utilizados no decorrer das etapas, nesse momento, foram revistas cuidadosamente e transcritas, no caso das entrevistas. Sucessivamente, ocorreu a organização e categorização dos dados de acordo com as características de cada Geração da Avaliação. Após a categorização das informações, partiremos para a descrição e a interpretação dos resultados. A descrição é apresentada em um formato de texto síntese para cada etapa do CEK e, concomitantemente, a interpretação feita, por meio da explo- 
ração e da compreensão dos significados descritos. Nesse sentindo, o movimento interpretativo das descrições constituirá de um modo circular entre a teorização, interpretação e compreensão.

\section{Resultados e discussão}

\section{Aporte Teórico}

A Avaliação como a conhecemos hoje, simplesmente, não surgiu do dia para noite. Ela é resultado de um processo de desenvolvimento de construção e de reconstrução que envolve inúmeras influências. Para melhor compreensão dessas transformações, Guba e Lincoln (1989), observando que a avaliação passou por uma evolução histórica, dividiram essa evolução em gerações, as chamadas Gerações da Avaliação de Guba e Lincoln (LIMA, 2008; VIANA, 2014).

A Primeira Geração da Avaliação, também conhecida como a Geração da Medida, influenciou os testes escolares que são utilizados há centenas de anos. Através deles procurava-se investigar se a criança demonstrava domínio dos "fatos". Os primeiros testes escolares foram administrados principalmente por via oral.

Vários fatores, direta ou indiretamente relacionados com os testes, desempenharam papel importante para o desenvolvimento desta primeira geração da avaliação. O primeiro desses fatores está relacionado com a utilização da abordagem das Ciências Físicas, como a utilização de tabelas matemáticas, por exemplo, ou para interpretar resultados das Ciências Sociais, incluindo a Educação. O segundo fator estimulante dá-se com o surgimento do movimento de gerenciamento científico no mundo dos negócios e da indústria.

Durante as décadas de 1920 e 1930 houve uma proliferação de testes escolares, produzidos de muitas formas. Em uma delas, em 1922, pela primeira vez, foi permitida a avaliação simultânea da posição relativa do aluno através de várias disciplinas. Durante esse período, os termos medição e avaliação eram usados como sinônimos.

Nesse contexto, Guba e Lincoln (1989) sustentam que:

Assim, a Primeira Geração de avaliação pode ser legitimamente chamada a geração da medida. O papel do avaliador era técnico; dele ou dela era esperado ter a sorte de conhecer todos os instrumentos disponíveis, de modo que qualquer variável para investigação poderia ser medida. Se não existissem instrumentos apropriados, era esperado do avaliador a experiência necessária para criá-los. E, é terrivelmente importante notar, que esta primeira geração ou senso técnico de avaliação persiste até hoje. (GUBA; LINCOLN, 1989, p. 26, tradução nossa).

Portanto, essa geração da avaliação era marcada pela reprodução do conteúdo e a busca por respostas objetivas por meio de instrumentos que apresentam características essencialmente quantitativas, que buscam quantificar, classificar, selecionar e conseguir resultados exatos e objetivos. Esse tipo de avaliação está diretamente ligado à abordagem tradicional de ensino (MIZUKAMI, 1986), em que a ação educativa está centrada no educador (o avaliador) e o educando (o avaliado) tem a função de reproduzir com exatidão as informações transmitidas pelo professor durante a aula. 
Diante da deficiência apresentada pela Primeira Geração, surge a Segunda Geração da Avaliação chamada também de Geração da Descrição ou por Objetivos. Essa geração emerge da necessidade de reformulação dos currículos escolares, em que a avaliação não era apenas focada no rendimento dos estudantes, mas caracterizada pela descrição de padrões, definidos pelos pontos fortes e fracos, utilizada para orientar aperfeiçoamentos e revisões.

Nesse contexto, os termos medir e avaliar não eram mais considerados equivalentes, mas como instrumentos que poderiam ser usados para o ato de avaliar. Assim, o avaliador não se preocupava apenas em medir os resultados alcançados, mas também em descrever os programas educativos e se os objetivos estabelecidos foram ou não alcançados. Como afirmam Guba e Lincoln (1989, p. 28, tradução nossa),

Assim, surgiu o que nós escolhemos chamar a Segunda Geração da avaliação, uma abordagem caracterizada pela descrição dos padrões de pontos fortes e fracos em relação a determinados objetivos declarados. O papel do avaliador era de descrever, embora os aspectos técnicos tenham sido mantidos. A medição já não era considerada como o equivalente de avaliação, mas foi redefinida como um dos vários instrumentos que podiam ser usados ao seu serviço.

No entanto, essa geração da avaliação ainda estava muito ligada aos aspectos quantitativos da avaliação e caracterizada pela abordagem comportamentalista (MIZUKAMI, 1986), na qual a avaliação está diretamente relacionada aos objetivos estabelecidos. Portanto, essa geração considera o estudante como um depósito de informações e está preocupada apenas se este atingiu de forma adequada os objetivos estabelecidos e propostos pelo programa até o final do processo.

Devido a algumas falhas da Segunda Geração, emerge a Terceira Geração da Avaliação, a chamada geração de Juízo de Valor. É nessa geração que se rompem os excessivos aspectos quantitativos carregados pelas gerações anteriores e em que se considera a descrição e o julgamento como base para o desenvolvimento da avaliação, como descrevem Guba e Lincoln (1989, p. 30, tradução nossa):

A chamada para incluir o julgamento no ato da avaliação, marcou o surgimento da avaliação de Terceira Geração, uma geração em que a avaliação foi caracterizado por esforços para chegar a julgamentos, e em que o avaliador assume o papel de juiz, mantendo as funções técnicas e descritivas anteriores.

Entretanto, a Geração do Julgamento apresenta algumas lacunas, pois ainda apresenta o professor como centro das decisões, apesar de ter avançado no sentido de ser utilizada não apenas para descrever os pontos fortes e fracos, mas também para tomada de decisão que buscará os caminhos para a aprendizagem frente aos resultados encontrados, estabelecendo o valor e mérito do programa, com a aplicação de diversos instrumentos avaliativos durante todo o processo, e não apenas no final como nas gerações anteriores (VIANA, 2014).

E mesmo essa geração da avaliação já se associando com a abordagem cognitivista (MIZUKAMI, 1986), em que busca desenvolver a inteligência e priorizar as atividades dos su- 
jeitos envolvidos, considerando-os integrantes de um contexto, colocando os erros e os acertos numa igualdade de patamar, concebendo que cada sujeito, cada estudante, tem uma maneira singular de ver o mundo e interpretar os fatos e superando as avaliações padronizadas, ainda assim Guba e Lincoln (1989) observam a ênfase na figura do professor.

Até o momento, pode-se observar que cada geração deu um passo à frente no que se refere à abordagem do processo e da metodologia. Porém, de acordo com Guba e Lincoln (1989), todas as três gerações continuam a apresentar falhas graves e necessitam de uma completa reconstrução. Uma dessas falhas está relacionada ao método científico que apoia as tendências gerenciais, que impõe a autoridade ao ponto de considerar "a verdade como inegociável”, ou seja, não há negociações possíveis sobre o que é verdade, e por a ciência ser livre de valores, outra falha ligada ao valor do pluralismo, a adesão ao paradigma científico alivia o avaliador de qualquer responsabilidade moral por suas ações. Assim, nenhuma das três gerações torna o avaliador moralmente responsável pela avaliação e pelo uso de seus resultados.

É notório que, ao longo do tempo, a construção da avaliação vai se tornando mais sofisticada, à medida que cada uma delas tenta superar as limitações encontradas nas gerações que a antecedem. No entanto, chegou-se ao ponto em que foi preciso elaborar uma nova construção de avaliação que atendesse às novas perspectivas de ensino e quebrasse com os aspectos quantitativos e restritos das três gerações de avaliação observadas.

Surge, neste contexto, uma nova avaliação, mediada pelo diálogo e negociação, uma avaliação construtivista responsiva, a Quarta Geração da Avaliação. De acordo com Guba e Lincoln (1989, p. 50, tradução nossa):

[...] avaliação de Quarta Geração é uma forma de avaliação em que as reivindicações, preocupações e questões das partes interessadas servem como focos organizacional (a base para determinar que informações é necessário), que é implementado dentro dos preceitos metodológicos do paradigma construtivista.

Essa geração é considerada emergente por ser um processo interativo e negociado. Assim, o papel do avaliador consiste em realizar uma avaliação em que todos os envolvidos, através do diálogo e da negociação, possam chegar a um consenso frente às reivindicações, preocupações e questões enfrentadas naquele momento. Isto posto, há uma interação e reintegração da avaliação. Não podemos esquecer que essa avaliação não exclui modos quantitativos, mas lida com qualquer informação que seja compassiva à reivindicação por resolver uma preocupação ou problema.

Esse tipo de avaliação, segundo Guba e Lincoln (1989), apresenta quatro fases. $\mathrm{Na}$ primeira fase, as partes interessadas são identificadas e são solicitadas para as reivindicações, preocupações e questões que queiram apresentar. Em seguida, as reivindicações, preocupações e questões levantadas por cada grupo de partes interessadas são introduzidas para todos os outros grupos, no intuito de que possam comentar o assunto, refutar, entrar em acordo ou qualquer outra reação que possa agradá-los. Na terceira fase, essas reivindicações, preocupações e questões são resolvidas. Na quarta e última fase, a negociação entre os grupos, sob a orientação do avaliador e utilizando as informações de avaliação que foram coletadas, realiza-se um esforço conjunto para chegar a um consenso sobre cada item disputado. Nesse contexto, além 
de construtivista, essa geração da avaliação está estreitamente ligada à abordagem sociocultural de ensino (MIZUKAMI, 1986).

No que diz respeito ainda às características da Avaliação de Quarta Geração, Lima (2008, p. 45) sustenta que:

[...] a Avaliação emancipadora proposta por Saul e a Avaliação mediadora proposta por Hoffmann têm aspectos importantes de Quarta Geração, por apresentarem uma Avaliação processual, contínua, participativa, emancipadora e mediadora, porém a perspectiva de Avaliação Formativa Reguladora, proposta por Silva apresenta além desses aspectos, outros, dentre os quais destacamos a ética, a pertinência cognitivo-epistemológica e a negociação, que é um aspecto tipicamente de uma Avaliação de Quarta Geração.

Ainda no contexto brasileiro, Viana (2014) apresenta um aporte teórico de uma avaliação de Quarta Geração, denominada Avaliação da Experiência, que apresenta como um dos pressupostos a avaliação como parte fundamental do processo de ensino e aprendizagem e oito princípios, entre eles, a negociação, a ética e a emancipação, essenciais para o processo avaliativo justo e inovador.

Contudo, nota-se que cada geração apresenta suas características, que muitas vezes são oriundas das características positivas apresentadas pelas gerações que a antecedem, e que vão sendo melhoradas de acordo com a necessidade. Ressalta-se que usar práticas inovadoras no ensino implica em abrir mão do controle sobre o processo e utilizar o diálogo e a negociação como mediadores do processo.

Após a descrição metodológica e a discussão teórica que sustenta a análise, apresentamos o Ciclo da Experiência vivenciado pelos professores.

\section{Primeira Etapa do Ciclo da Experiência (Antecipação)}

Professor 1: O ciclo inicia-se nesse momento, onde é realizada uma entrevista com o professor. Nessa etapa, buscamos refletir sobre as concepções do professor, a partir de elementos considerados por ele sobre a Avaliação da Aprendizagem nas atividades experimentais. $\mathrm{O}$ Professor 1 afirma que as suas aulas são todas teóricas e justifica pela carga horária estabelecida para as turmas do primeiro ano, que corresponde a uma aula semanal no primeiro semestre e duas aulas semanais no segundo semestre: "[...] para faz̧er atividades práticas en teria que ter detrimento em alguns conteúdos o que provocaria uma defasagem, então eu prefiro trabalhar o primeiro ano mais teoricamente sem as aulas práticas".

Ao final do processo considera os pontos fortes e fracos determinados a partir dos objetivos estabelecidos e definidos por ele. Essa forma de avaliar é característica de uma Avaliação de Segunda Geração, na qual o professor é o centro das decisões e estabelece todos os instrumentos avaliativos antes do processo, tomando como base apenas os objetivos de ensino. Dessa forma, ao final do processo, limita-se a descrever os pontos fortes e fracos de acordo com esses objetivos. No que se refere aos Instrumentos Avaliativos, o Professor 1 utiliza-se de diversos instrumentos, como rodas de conversa, observações e relatórios, mas enfatiza os relatórios escritos pelo fato de que, ele afirma: "[...] a observação é um pouco falha e para depois eu ter a certeza da pontuação nessa atividade". 
Apesar do Professor utilizar instrumentos avaliativos diversificados, ele enfatiza apenas um, no caso, o relatório, que é um instrumento individual e normalmente padronizado, pois segue um modelo. Assim mais uma vez, apresenta características de Segunda Geração da Avaliação.

Professor 2: O Processo para o Professor 2 está centrado na aprendizagem dos estudantes e faz uso das atividades experimentais, pois segundo ele, o desenvolvimento dessa atividade proporciona "construir junto com o aluno todo conteúdo trabalhado, oportunizando a vivência de acertos e erros, oportunizá-lo a ter contato com o reagente com as vidrarias e construir a conclusão das leis experimentais, das leis teóricas e de todo um trabalho vivenciado nos livros". Assim, diante da exposição oral do Professor 2, é notada a importância que ele dá à aprendizagem do estudante, e ao papel que o professor tem de mediar, sem perder seu papel técnico que agora tem por objetivo a tomada de decisões frente aos resultados encontrados durante o processo de ensino-aprendizagem. Isso é característico da Terceira Geração da Avaliação.

Os Instrumentos Avaliativos utilizados pelo Professor 2 são: relatório, perguntas e respostas direcionadas às equipes e a observação. Justifica-os afirmando que: "[...] o relatório, por ser escrito, é o momento de o aluno colocar aquilo que ele vivenciou naquela prática. A observação, porque tudo parte da observação. Ela é o ponto inicial para construção do conbecimento". E ressalta ainda que os instrumentos mais importantes são o interesse e o compromisso do aluno, que são os pontos principais da observação.

Por serem aplicados instrumentos avaliativos diversificados e não padronizados, que permitem a tomada de decisão frente aos resultados encontrados, e por estar preocupado com a aprendizagem do estudante, considerando seus erros e acertos e afirmando que cada estudante tem uma maneira singular de ver o mundo e interpretar os fatos, o Professor 2 traz indicativos de Terceira Geração da Avaliação. Apesar de todos os aspectos qualitativos, o processo decisório ainda está centralizado no professor.

\section{Segunda Etapa do Ciclo da Experiência (Investimento)}

Nesse momento foram realizados estudos e debates do texto "Atividades experimentais e avaliação da aprendizagem: uma via de mão única", da primeira autora deste artigo, que traz em seu conteúdo reflexões sobre a importância das atividades experimentais na construção do conhecimento em Química, como também as reflexões sobre a prática avaliativa e as Gerações da Avaliação. O objetivo desse momento foi proporcionar aos professores uma reflexão sobre os elementos discutidos e, segundo Lima (2008), prepará-los cognitivamente para o Encontro, momento em que eles checam suas teorias formuladas na etapa do Investimento.

Após a leitura e discussão do texto proposto, buscamos saber as percepções dos professores acerca do texto. Segundo eles, foi um texto bom e de fácil leitura. Perguntados se já possuíam conhecimento sobre novas perspectivas de avaliação:

Professor 1: afirmou que não tinha conhecimento das Gerações da Avaliação. No que se refere a sua prática avaliativa em atividades experimentais, que está próximo da Segunda Geração "porque, além de ter as características da avaliação por medida da primeira geração, também posso descrever os pontos que são fortes e fracos em relação à aprendizagem daquele conteúdo".

Professor 2: afirmou que tinha conhecimento sobre as novas perspectivas da avaliação e justificou que a avaliação sempre é alvo de discussões em reuniões. Afirmou ainda que: “[...] a avaliação é sempre um processo colocado na necessidade de melhoria". Quando perguntado se em algum 
momento do texto identificou sua prática avaliativa, o mesmo afirmou que vivencia um pouco da cada geração, mas que a Terceira Geração da Avaliação é a que mais se aproxima de sua prática.

Em seguida, questionamos os Professores se seria possível vivenciar uma Avaliação de Quarta Geração. Obtivemos as seguintes respostas:

Professor 1: segundo ele, "[...] a maior dificuldade não está nos alunos, está em nós professores chegarmos a nivel de diálogo. Porque para os professores, com formação de outra década, é difícil trabalhar por esse caminho, pela negociação". E sustenta que se essa prática avaliativa fosse desenvolvida em nível de instituição e que se ela fornecesse subsídios didáticos e metodológicos para isso, a sua vivência se tornaria mais fácil de acontecer.

Professor 2: Ele respondeu que sim, mas ressaltou que "[...] para isso, essa prática avaliativa deveria estar descrita no PPP da escola". Para esse professor, a efetivação dessa vivência só poderia ocorrer se estivesse estabelecida para todos os professores dentro do Projeto Político Pedagógico da Instituição para a Educação Básica Integrada, pois, segundo ele, vivenciar essa prática em apenas uma disciplina teria um grau de dificuldade grande.

Ao término desse momento de debate e ressignificação de conceitos e saberes, seguimos para o Encontro, momento em que foi observada a prática avaliativa dos Professores no desenvolvimento de uma atividade experimental.

\section{Terceira Etapa do Ciclo da Experiência (Encontro)}

Nesse momento, ocorreu a vivência da prática avaliativa dos Professores:

Professor 1: O conteúdo vivenciado durante a aula foi Ligações químicas, e a atividade experimental desenvolvida foi Identificando algumas propriedades das ligações químicas.

Em suas aulas, o Professor 1 faz uso direto do livro didático para discutir os conceitos e realizar atividades. Inicia a aula abordando os conceitos sobre as Ligações, sua formação e propriedades. $\mathrm{Na}$ aula decorrente, faz uma breve revisão dos conhecimentos construídos nas aulas passadas com perguntas diretas aos estudantes, os quais interagem bem e conseguem responder a todos os questionamentos. Assim se inicia as resoluções de exercícios com os estudantes, direcionados pelo Professor 1. Os estudantes vão lendo as questões descritas no livro e o Professor 1 faz sua resolução no quadro. Concomitantemente questiona os estudantes, que interagem bem e levantam muitos questionamentos entre eles e com o Professor. Vale ressaltar a preocupação dos estudantes sobre a avaliação daquele conteúdo.

Finalizando o conteúdo, o Professor 1 faz a aplicação do experimento, identificando algumas propriedades das Ligações químicas, buscando identificar o tipo de ligação a partir de algumas propriedades. Para esse experimento, o Professor 1 verifica propriedades como: o estado físico, ponto de fusão e ponto de ebulição de algumas substâncias. As substâncias trabalhadas foram: vinagre, cloreto de potássio, álcool, sulfato de cobre, sacarose, carbonato de cálcio. A realização da atividade experimental iniciou-se com a distribuição do roteiro, composto por um breve texto sobre as Ligações químicas e suas propriedades.

O modo como o professor conduziu a atividade experimental caracterizou-se como uma abordagem demonstrativa, mesmo sendo manuseada pelos estudantes. Uma vez que a abordagem teórica já havia sido trabalhada e o objetivo da prática era de reforçar os conceitos. A atividade foi desenvolvida no laboratório de Química e os materiais para realização do experimento já estavam dispostos sobre a bancada. O Professor 1 solicitou que os estudantes formassem 3 (três) grupos e se direcionassem a uma bancada. 
Após todos se acomodarem, o Professor 1 deu algumas instruções sobre técnicas de segurança no laboratório, pois aqueles estudantes estavam ali pela primeira vez. Em seguida, pediu de forma direta a cada aluno que lesse parte do texto em voz alta. Após a leitura, mostrou os materiais que seriam utilizados e explicou os procedimentos. Os estudantes não estavam preocupados se aquela atividade seria ou não avaliativa, mas estavam curiosos e entusiasmados pelo fato de estarem ali investigando alguma coisa.

O Professor 1 segue de grupo em grupo, observando e instruindo a realização do experimento. À medida que cada grupo vai identificando suas substâncias, os estudantes discutem suas propriedades, comparando o que eles viram na abordagem teórica com a experiência proporcionada pela atividade. Após todos os grupos realizarem e anotarem suas observações, o Professor 1 começou a questioná-los sobre o que observaram e o porquê, direcionando as respostas para a confirmação da teoria previamente apresentada e discutida. A aula é finalizada quando o Professor 1 retoma ao objetivo da aula, resgata as principais observações e busca saber se os estudantes conseguiram alcançar o objetivo da mesma.

A atividade experimental desenvolvida, segundo o Professor 1, não iria fazer parte da avaliação daquele conteúdo. Mas, ocorreu uma avaliação específica para a atividade em que o Professor 1 buscou identificar, por meio da observação, se os estudantes conseguiram alcançar o objetivo pré-estabelecido: identificar as Ligações químicas por meio de suas propriedades. Para esse professor, a avaliação da disciplina dar-se-á por um texto investigativo com questões e a prova escrita.

Portanto, o Professor 1, lembrando que na etapa da antecipação afirmou não realizar atividades experimentais em suas aulas, desenvolveu a experimentação de modo a assegurar a aprendizagem dos estudantes, mesmo não considerando essa atividade parte do processo avaliativo da disciplina para a revisão do processo ensino-aprendizagem. E, mesmo se preocupando com a compreensão dos estudantes, sua principal meta foi atingir os objetivos de ensino. Essa forma de conceber o processo é característica da Segunda Geração da Avaliação.

Professor 2: O conteúdo trabalhado na aula foi Cinética Química e a atividade experimental foi realizada pelos estudantes, depois de pré-estabelecida pelo Professor 2 para cada grupo. Os experimentos desenvolvidos foram: (a) velocidade da reação - etapa I; (b) velocidade da reação - etapa II; (c) velocidade da reação - etapa III; e (d) catalase - ação enzimática.

O Professor 2, a cada aula ministrada, expôs os conhecimentos teóricos e científicos e entregou uma ficha de exercício sobre o conteúdo trabalhado, que compõe a avaliação da disciplina. Para a abordagem da cinética química, foram aplicadas 4 (quatro) fichas de exercício. A resolução dos exercícios da ficha se dá em dois momentos: o primeiro, na sala de aula, quando o Professor 2 convida os estudantes a fazerem a resolução de algumas questões no quadro e, à medida que vão respondendo e aparecendo as dúvidas, ele media e, sempre que necessário, retorna a explicar o princípio teórico para a resolução da questão.

Os estudantes respondem muito bem a aplicação desses exercícios, pois questionam e discutem entre si sobre a resolução, sempre mediados pelo professor, que busca a atenção deles para alguns pontos importantes, tira dúvidas e vai para junto do estudante sempre que solicitado. O Professor 2 se mostra sempre atento aos questionamentos dos estudantes e preocupado com a sua aprendizagem.

Ao finalizar o conteúdo teórico, o Professor 2 solicita aos estudantes a apresentação de experimentos para trabalhar de forma prática os conceitos anteriormente estudados. Para 
isso, ele estabelece uma ficha específica para o desenvolvimento dessa atividade: nela constam os objetivos pretendidos, os critérios pelos quais serão avaliados, os procedimentos dos experimentos, o experimento que irão desenvolver e a data de apresentação.

Todos os experimentos foram realizados e apresentados no laboratório. O Professor 2 preocupou-se em escolher experimentos simples, com utilização de materiais de baixo custo, mas que abordassem de forma contextualizada os conceitos da Cinética Química.

Durante as apresentações dos experimentos pelos estudantes, o Professor 2 se comportou como mediador entre as discussões e as problemáticas que surgiam, mas não tirava a autonomia dos estudantes frente às discussões dos fenômenos apresentados e discutidos. As atividades organizadas nesse formato oportunizaram uma interação muito boa entre os alunos, que discutiram e testaram suas hipóteses à medida que os grupos se apresentavam.

Após a apresentação, os componentes de cada grupo eram convidados à avaliação pelo Professor 2, a partir de cada critério utilizado para avaliação: clareza, segurança, organização e conclusões apresentadas pelo experimento, anteriormente disponibilizada na ficha. Para cada item, o professor buscou saber dos estudantes suas concepções e posturas frente a cada critério, justificando-os e pontuando-os. Portanto, para o Professor 2, a avaliação do conteúdo de Cinética Química foi a resolução das fichas de exercícios, o desenvolvimento da prática experimental e a prova escrita, não como meios de pontuação apenas, mas para receber respostas de como está o processo de ensino-aprendizagem e se o conhecimento se tornou significativo para aqueles estudantes.

Seguiremos para a confirmação ou refutação das hipóteses levantadas na análise preliminar da prática avaliativa dos Professores.

\section{Quarta etapa do ciclo da experiência (Confirmação ou Desconfirmação)}

Nessa etapa analisamos as aproximações e distanciamentos da prática avaliativa dos Professores com a Avaliação de Quarta Geração confrontando os elementos evidenciados na antecipação diante da vivencia da experiencia realizada no encontro.

Professor 1: O Processo foi definido e estabelecido pelo Professor 1, tanto no momento das aulas teóricas quanto da aula prática, por meio de exposição e demonstração do conteúdo, respectivamente. Como também a metodologia estava pré-estabelecida, em que a atividade experimental seguia rigorosamente um roteiro, caracterizou-se uma avaliação por objetivos pré-estabelecidos, Avaliação de Segunda Geração.

Entretanto, a preocupação do Professor 1 com a compreensão dos estudantes durante o processo ensino-aprendizagem, quando os questionava, tirava dúvidas e mediava discussões, retrata traços de uma Avaliação de Terceira Geração. Nesse elemento, além de confirmar suas concepções apresentadas no primeiro momento, o Professor 1 dá um passo para o desenvolvimento de avaliações mais qualitativas, como é o caso da Terceira Geração, mas ainda se mantém distante da Avaliação de Quarta Geração por, principalmente, centralizar o processo decisório.

Em relação aos Instrumentos Avaliativos para a atividade experimental, o Professor 1 fez uso da observação, mas esse quesito não contaria como forma de avaliação do conteúdo trabalhado naquele momento. Porém, considera que poderia, em outras vivências, pensar em instrumentos avaliativos para essa prática, pois como havia dito na primeira etapa, não trabalhava com aulas experimentais com as turmas de primeiro ano. Afirmou que a sua avaliação seria 
composta por um texto investigativo com questões e uma prova escrita. Assim desconfirmamos a Avaliação de Terceira Geração e confirmamos apenas características de uma Avaliação de Segunda Geração.

De acordo com o Professor 1, a maior parte dos seus construtos teriam sido mantidos para aquela vivência, mas que para vivências posteriores, os estudos sobre avaliação poderiam integrar sua prática.

Professor 2: O Processo na prática do Professor 2 se dá por meio da negociação e diálogo, no momento em que o Professor 2 convida seus alunos a realizarem a autoavaliação no processo avaliativo. E que proporciona a autonomia e criticidade dos estudantes. Assim está se desenvolvendo uma avaliação democrática e participativa por meio do compartilhamento de responsabilidades, mediadas pela negociação. Nesse elemento evidenciamos a prática avaliativa de Quarta Geração. Como no primeiro momento, o Professor 2 apresentava concepções de Terceira Geração da Avaliação, consideramos que os momentos de discussões e ressignificação da avaliação proporcionaram essa vivência.

Sobre a compreensão dos estudantes, o Professor 2 sempre esteve atento aos questionamentos feitos por eles e, no momento em que propôs essa atividade experimental para desenvolvimento dos estudantes e buscou avaliá-los por meio da autoavaliação, propôs uma avaliação responsiva mediada pela negociação em que o importante não era o estudante acertar ou errar, mas sim construir os conceitos e saber aplicá-los. Portanto, assim como nos demais elementos, o Professor 2 desenvolveu uma Avaliação de Quarta Geração, desconfirmando e ressignificando sua prática avaliativa.

Os Instrumentos Avaliativos utilizados pelo Professor 2 foram diversificados. Além de se comunicarem, eles complementavam-se, pois, além de aplicar os conteúdos científicos abordados pela Cinética Química, o Professor 2 proporcionou aos estudantes observá-los por meio das atividades experimentais, e incentivá-los à investigação, tornando a aprendizagem mais significativa e aplicável em seu cotidiano. Ele conseguiu também, por meio da negociação, proporcionar a formação crítica dos estudantes, apresentando prática da Quarta Geração da Avaliação.

Portanto, a maioria das análises foi desconfirmada pelo Professor 2, que desenvolveu uma avaliação de Quarta Geração durante a vivência do CEK, mostrando que há a possibilidade do estudante participar do processo avaliativo.

\section{Quinta etapa do ciclo da experiência (Revisão Construtiva)}

Fechando o CEK, foi realizada uma entrevista semiestruturada em que buscamos saber se os professores vivenciaram uma experiência, segundo Kelly (1963), em avaliação.

Professor 1: ao perguntarmos ao Professor 1 se as leituras e debates sobre as novas perspectivas de avaliação para as atividades experimentais auxiliaram para uma reflexão sobre a sua prática avaliativa, ele respondeu que sim, e justificou afirmando que as discussões vivenciadas no segundo momento foram importantes para que pudesse repensar a sua prática avaliativa e o desenvolvimento de atividades experimentais.

Em seguida, perguntamos se ele considerou ter vivenciado uma experiência em avaliação e como se sentiu fazendo parte da pesquisa. O Professor 1 afirmou que sim, e que, mesmo não apresentando aproximações com a Quarta Geração da Avaliação, pode verificar com a vivência 
da aula experimental, que os alunos se sentiram motivados a aprender. Afirmou ainda que, no decorrer dos encontros, ele pode refletir sua prática pedagógica como um todo e verificar o quanto é importante desenvolver atividades experimentais, mesmo com uma carga horária reduzida.

Posteriormente, perguntamos ao Professor 1 se após a vivência do CEK percebeu alguma mudança em suas concepções. Respondeu que sim e afirmou ainda que a vivência da atividade experimental lhe proporcionou a reflexão das contribuições do desenvolvimento da experimentação nas aulas de Química, porque deixaria os limites de estar apenas praticando resoluções de exercícios e utilizando o livro didático. Por fim, procuramos saber do Professor 1 se ele considerou importante o acesso dos resultados da pesquisa antes dela ser publicada. Ele respondeu positivamente e acrescentou que é importante e interessante conhecermos sobre nossa prática por meio da visão externa e podermos discutir sobre isso.

Professor 2: Ao perguntarmos ao Professor 2 se as leituras e debates sobre as novas perspectivas de avaliação para as atividades experimentais auxiliaram para uma reflexão sobre a sua prática avaliativa, ele respondeu que sim, e que os textos só vieram somar no desenvolvimento de sua prática. Ao ser questionado se considerou ter vivenciado uma experiência em avaliação, respondeu que sim, porém já exercitava essa prática avaliativa apenas na última unidade. Em seguida, questionamos como se sentiu fazendo parte da pesquisa, e ele afirmou que: "[...] a pesquisa foi um conbecimento a mais, uma leitura moderna, pois considero que a educação está sempre em movimento".

Posteriormente, ao ser questionado se após a vivência do CEK ocorreu alguma mudança em suas concepções, o Professor 2 respondeu que sim e acrescentou: '[...] a nossa prática está sempre aberta a modificaçôes" e mostrou-se surpreso ao observar o interesse dos estudantes diante daquela atividade. Por fim, perguntamos ao Professor 2 se ele considerou importante ter acesso aos resultados da pesquisa antes de ser publicada, ouvimos que seria até uma exigência sua, caso não o tivéssemos comunicado, e considerou bastante importante termos essa metodologia em nossa pesquisa.

\section{Conclusões}

A partir dos resultados e discussões apresentadas no âmbito da pesquisa, podemos considerar que a Avaliação no Ensino da Química é um tema pertinente e relevante no desenvolvimento dessa ciência na educação. Dessa forma, os professores, sujeitos da pesquisa, mesmo apresentando algumas práticas distantes da Quarta Geração da Avaliação, ao passar pelo Ciclo da Experiência Kellyana tiveram alguns de seus elementos reconstruídos. A cada etapa do ciclo, os professores identificavam a importância do desenvolvimento de atividades experimentais, associadas a uma avaliação que proporcionasse uma reflexão sobre a aprendizagem dos estudantes.

No caso do Professor 1, por estar preso a uma abordagem de avaliação de Segunda Geração, após a experiência ocorreram algumas modificações em suas concepções, apresentando aspectos da Terceira Geração. Dessa forma, o professor, apesar de manter alguns de seus construtos, teve modificações em seus repertórios e se aproximou um pouco mais da Quarta Geração. No entanto, deve ser proporcionada a esse professor uma continuação de intervenções, para que possa, aos poucos e a cada intervenção, ampliar seus construtos pessoais acerca da avaliação. 
O Professor 2 desenvolveu mais aspectos da Avaliação de Quarta Geração, pois, inicialmente, os seus construtos estavam ligados à Terceira Geração e, após a vivência do CEK, pode reconstruir o seu repertório e desenvolver diversos aspectos da Avaliação de Quarta Geração.

Consequentemente, podemos identificar que a partir da vivência do Ciclo da Experiência Kellyana houve uma reconstrução significativa dos elementos estabelecidos em relação ao repertório de construtos apresentados pelos professores, proporcionando uma aproximação de uma avaliação mais emergente e até mesmo da Quarta Geração da Avaliação, como foi o caso do Professor 2.

Finalmente, pudemos observar as contribuições de momentos que podem oportunizar uma reflexão sobre a prática pedagógica: no caso do estudo, a prática experimental e avaliativa. Uma vez que os professores conseguiram identificar a importância do seu desenvolvimento para auxiliar a aprendizagem dos estudantes e inovar as suas práticas pedagógicas, ressaltamos a importância de formações continuadas para os educadores, pois é através de momentos de estudos e reflexões que é possível auxiliar na renovação do ensino de ciências, e mais especificamente, no ensino de Química.

\section{Referências}

ALVES FILHO, J. P. Atividades experimentais: do método à prática construtivista. 2000. Tese (Doutorado em Educação) - Centro de Ciências da Educação, Universidade Federal de Santa Catarina, Florianópolis, 2000. Disponível em: <http://repositorio.ufsc.br/xmlui/ handle/123456789/79015>. Acesso em: 30 mar. 2017.

BARROS, M. A.; BASTOS, H. F. B. N. Investigando o uso do ciclo da experiência kellyana na compreensão do conceito de difração de elétrons. Caderno Brasileiro de Ensino de Física, Florianópolis, v. 24, n. 1, p. 26-49, 2008. Disponível em: < https://periodicos.ufsc.br/ index.php/fisica/article/view/1549/12757>. Acesso em: 31 mar. 2017.

BASTOS, H. F. B. N. Changing teachers' practice: towards a constructivist methodology of physics teaching. Thesis (Doctor of Philosophy) - Department of Educational Studies, University of Surrey, Guildford, 1992. Disponível em: < http://epubs.surrey.ac.uk/919/1/ fulltext.pdf > . Acesso em: 30 mar. 2017.

BRASIL. Ministério da Educação. Orientações curriculares para o ensino médio: ciências da natureza, matemática e suas tecnologias. Brasília, 2006.

ESTEBAN, M. P. S. Pesquisa qualitativa em educação: fundamentos e tradições. Porto Alegre: AMGH, 2010.

FREIRE, P. Pedagogia da autonomia: saberes necessários à prática educativa. São Paulo: Paz e Terra, 1996.

GUBA, E. G.; LINCOLN, Y. S. Fourth generation evaluation. London: Sage, 1989.

KELLY, G. A. A theory of personality: the psychology of personal constructs. New York: W. W. Norton, 1963. 
LIMA, K. S. Compreendendo as concepções de avaliação de professores de física através da teoria dos construtos pessoais. 2008. 163f. Dissertação (Ensino de Ciências) Departamento de Educação, Universidade Federal Rural de Pernambuco, Recife, 2008.

LUDKE, M.; ANDRÉ, M. E. D. A. Pesquisa em educação: abordagens qualitativas. São Paulo, EPU, 1986.

MIZUKAMI, M. G. N. Ensino: as abordagens do processo. São Paulo: EPU, 1986.

THIOLLENT, M. Metodologia da pesquisa-ação. São Paulo: Cortez, 1985.

TRIPP, D. Pesquisa-ação: uma introdução metodológica. Educação e Pesquisa, São Paulo, v. 31, n. 3, p. 443-466, 2005. Disponível em: <http://dx.doi.org/10.1590/S151797022005000300009>. Acesso em: 30 mar. 2017.

VIANA, K. S. L. Avaliação da experiência: uma perspectiva de avaliação para o ensino das ciências da natureza. 2014. 202 f. Tese (Doutorado em Ensino das Ciências) - Universidade Federal de Pernambuco, Recife, 2014.

Artigo recebido em 18/07/2015. Aceito em 02/11/2016.

Endereço para contato: Rua Manuel José da Silva, 19, centro, CEP 55840-000, Lagoa de Itaenga, PE, Brasil. 